\title{
A Recent Regulatory Update on Consequences of Data Integrity Issues and its Management in Pharmaceutical Scenario
}

\author{
Remya James', Srija Das', Anjali Kumari', Mikal Rekdal², Girish Pai Kulyadi, \\ Muddukrishna Badamane Sathyanarayana ${ }^{1, *}$
}

1'Department of Pharmaceutical Quality Assurance, Manipal College of Pharmaceutical Sciences, Manipal Academy of Higher Education, Manipal, Karnataka, INDIA.

${ }^{2}$ Department of Chemical Engineering, Norwegian University of Science and Technology, Trondheim, NORWAY.

${ }^{3}$ Department of Pharmaceutics, Manipal College of Pharmaceutical Sciences, Manipal Academy of Higher Education, Manipal, Karnataka, INDIA.

\begin{abstract}
Purpose: Pharmaceutical industry ensures that data entered for various steps of drug development is accurate, which gives us confidence that the drugs produced by the industry are within specified parameters. Data integrity indicates sustaining and assuring the accuracy and reliability of data throughout the life cycle of the product. Over the years, numerous leading regulatory authorities have communicated their expectations in the form of regulations and guidance documents from the US FDA, MHRA, EMA, PIC/S and WHO, which address data management and data integrity issues. However, with an increase in digitalisation and the role of global markets, data integrity failures have increased. This results in recalls of products, warning letters, seizures, legal action and ultimately the potential for patient harm. Materials and Methods: Over the last few years, several regulatory agencies have acted against data integrity deficiencies in the pharmaceutical industry. In 2016, more than 50\% of MHRA warning letters involved data integrity lapses for computerized systems were observed compared to year 2015. Broadly, the U.S. approximately has received 15 percent of the warning letters, European countries have received approximately 8 percent and the rest of the world claims approximately 15 percent from FDA in the years 2008-2018. MHRA published a guidance document on data integrity in the March 2015 and its revised draft copy was published in March 2018 which applies to GxP systems. Results: From a quality standpoint, data integrity plays a pivotal role in a company's quality system. Data management and data governance should be efficiently integrated into the quality management system. Conclusion: This article represents the evaluation of warning letters from the last ten years regarding data integrity deficiencies.
\end{abstract}

Key words: Data integrity, Warning letters, Audit, Inspection, Quality system and Regulatory.

\section{INTRODUCTION ${ }^{1-6}$}

Data integrity is an important part of the pharmaceutical quality management system which guarantees that medicines produced are of the desired quality, which relies on product quality. Product quality depends on the data generated. Data integrity gives the assurance that records i.e. electronic and paper records, are precise, intact, accurate and well maintained in their original form and aims to prevent fabrication of information. Data integrity is of profound importance to regulators for several of reasons, which include patient safety, process, and product quality. The regulator's opinion on the personnel and the company greatly depends on the integrity and confidence provided by the data. Data integrity is critical to the design, execution and use of any system
Submission Date: 13-01-2021; Revision Date: 16-03-2021; Accepted Date: 03-05-2021

DOI: 10.5530/ijper.55.2s.134 Correspondence: Dr. Muddukrishna BS (M.Pharm)

Department of Pharmaceutical Quality Assurance, Manipal College of Pharmaceutical Sciences, Manipal Academy of Higher Education, Manipal-576104, Karnataka, INDIA.

Phone no: $+91-2922482$

Email id: krishna.mbs@manipal.edu

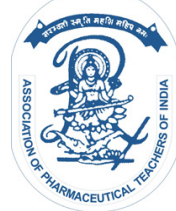

www.ijper.org 
that stores and retrieves necessary data. Data integrity has always been a sensitive topic in the pharmaceutical industry, but it has gained more importance recently due to focus of regulatory authorities.

Assurance of data integrity indicates protecting the original data from any unintentional or deliberate modification, fabrication, deception or even elimination of data. The impact of violation can lead to loss of customer satisfaction and confidence in the company. The customers may not get the received effect of the medicine, their safety could be conceded and can affect the organization's reputation.

The FDA, MHRA, European Medicines Agency (EMA) and Pharmaceutical Inspection Convention and Pharmaceutical Inspection Co-operation Scheme (PIC/S) have published various publications in last few years to provide guidance on data integrity. Regulatory agencies have emphasised more on data integrity issues since they found some major cGMP failures which will affect the product quality, safety and efficacy. It is always better to be proactive against data integrity issues, rather than acting when the problem arises.

New guidelines

- March 2015 MHRA GMP

- April 2016 FDA

- May 2016 WHO GxP

- July 2016 MHRA GxP

- August 2016 EMA Q andA

- August 2016 PICs GMP/ GDP

- March 2018 MHRA GMP

\section{Alcoa concept}

The FDA first illustrated the abbreviation $A L C O A$, which refers to attributable, legible, contemporaneous, original and accurate. Other regulatory organisations slowly amended these keywords which evolved with time.

$>$ Attributable: Who acquired the data or executed an action and when was it acquired?

$>$ Original: Raw data or source data must be available in original form or true copy.

$>$ Contemporaneous: Data documented at the time of the activity.

> Legible: Data must be in a legible format and permanent during the entire retention time.

$>$ Accurate: Data must contain meaning and metadata Now ALCOA Plus

Regulations change over the years and ALCOA has also evolved over the years. Some more words were included to define the attributes of good documentation practise. They are:

$>$ Enduring: Truth.

> Available: Easy or possible to get or use, or present or ready to use.

$>$ Accessible: Able to be reached or approached, or able to be used or obtained.

$>$ Complete: Not lacking anything.

> Consistent: Always acting or behaving the same way.

> Credible: Able to be believed or good enough to be effective.

$>$ Corroborated: To support or help prove by providing information or evidence.

\section{Factors Affecting Data Integrity ${ }^{6}$}

There are various factors affecting data integrity. The following Figure 1 summarizes the factors affecting data integrity.

Processes Essential for Safeguarding Data Integrity

The key factors which are essential for data integrity processes are:

$>$ Organisational:

- Management of documents and records with guidance on good documentation practices

- Management of audits and self-inspections with coverage of data integrity topics

- Management of quality risks with mechanisms for prevention, detection and escalation of breaches of data integrity

- Management of third parties with provisions for quality agreements that include clear requirements for protection of data integrity
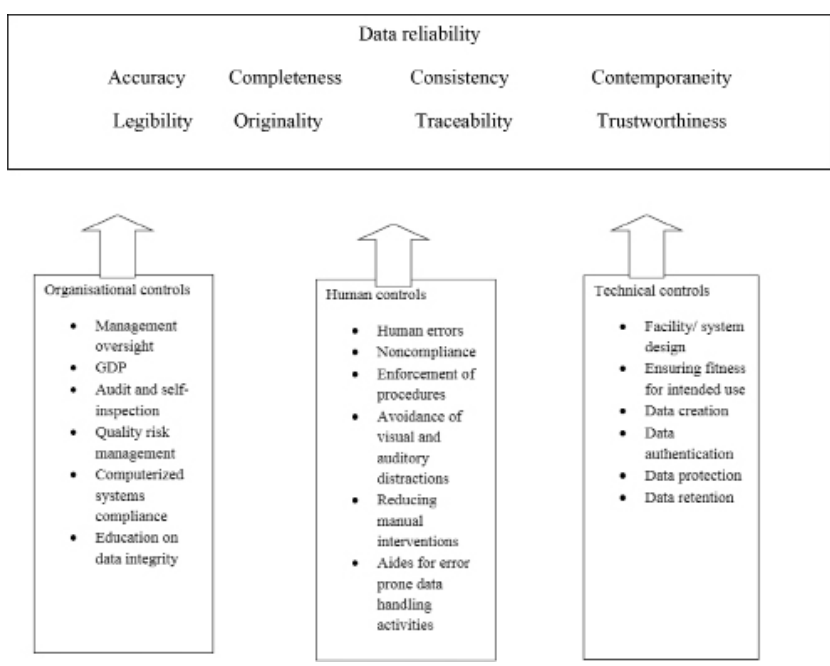

Figure 1: Factors Affecting Data Integrity. 
> Technical: Management of computerized systems compliance with clear requirements for data integrity from a design, validation and maintenance perspective

$>$ Human: Management of human factors with mechanisms for prevention of human errors and violations affecting data integrity. Provision of training on data integrity and ethics program

\section{Examples of Data Integrity Problems ${ }^{6}$}

$>$ Fabricating data

$>$ Discarding data

$>$ Recording wrong data

$>$ Back-dating or advance-dating

$>$ Making a false statement, a wrong statement, an omission of a fact or a statement which does not show evidence to an actual event

$>$ Submitting unreliable data

$>$ Replicating existing data as new data

$>$ Keeping duplicate sets of records

$>$ Not saving electronic or hard copy data

$>$ Not recording activities contemporaneously

$>$ Manipulation of analytical procedures or data to obtain passing results

> Carrying out multiple analysis with the same sample without proper reasoning

$>$ Trying to manipulate not well-defined analytical methods

$>$ Discounting failing test results without justification

$>$ Process modifications which are not justified and reported

$>$ Showing that the manufacturing site manufactures the drug, but it does not manufacture the drug as described in the drug master file

$>$ Supervisor approval by signing analyst or operator work without reviewing the raw data

> Management supervising key GxP operations not present when activities are going on

\section{Improving Data Integrity in Pharma Industries Training}

Creating awareness about the company's data integrity policy to the employees and new employees is to be made clear through scheduled training programmes conducted by experienced personnel. To make it easier to understand, it is to be oriented in various languages. This is vital since most of the errors or data integrity issues at the workplace are originated due to humans. These human errors can be prevented by appropriate training and by making the employees believe that these changes do make a huge impact on the quality of the medicines manufactured at the facility. They should understand that the impact of carelessness or fraud will ultimately affect the patients' lives. Training should be given to technical and non-technical operating staff. Data integrity culture should be followed through data integrity policies and Standard Operating Procedure.

Quality Culture: For maintaining data integrity in the company, the management should make personnel create awareness about the importance of their role in safeguarding data integrity and the impact of their activities on the quality of product and patient safety. The Standard Operating Procedure for data integrity should be followed efficiently by all personnel working in the company. A code of ethics should be strictly followed and it should reflect the management's attitude towards quality. Management should try to create a quality culture in which personnel are encouraged to freely communicate about failures and errors, so that corrective and preventive actions can be taken care of accordingly. The flow of information between all levels of the organization should be permitted.

\section{Computerized Systems}

Computer systems should have enough and suitable controls to prevent and detect unauthorized access or changes to data. Record should be maintained of any change made as to by whom and when the change was made. Access to folder deletion software installation and user privileges should be controlled. Computer system validation checks should be done in order to discern invalid or altered records. Computerised systems which are connected to other systems and are responsible for exchange of data electronically, should have a suitable number of checks for the secure entry of data to minimize the risks. A secure location should be allotted for backups of all data to prevent intentional or unintentional damage. In case of data review, there must be regular internal and external audits and verification of the attendance, log books and presence of the person. The frequency of data review should also be increased.

\section{Electronic Systems}

Biometric signatures are a method to verify an operative's identity based on measurement of an individual's physical features which are unique and measurable to that individual. For example, voice prints, hand prints and retinal scans. These signatures must consist of two distinctive components and must be used by the genuine owner. The system ensures that no two individuals have the same combination of identification codes and it should be periodically checked, recalled or revised, which is a necessary step in maintaining data integrity within electronic systems. 


\section{Better Communication}

Communication is very important to minimize the problems related to data integrity within the company. Workflow can be simplified by adopting best practise of predefined workflows which will reduce complexity. With the onset of modern tools such as LIMS, ELN and LES, the challenge to the industry is to pair a instrument with a computer system which needs to be loaded with the software application. This significantly lessens the barrier to integrate the instruments which will contribute to reducing the challenges related to data integrity.

\section{MATERIASL AND METHODS ${ }^{7-18}$}

The following data were collected from the warning letters available from the site of FDA.

Figure 2 and Table 1 represents the information of last 10 years, from 2008-2018. The number of warning letters received by different countries regarding data integrity has been represented. There has been a marked increase in the number of warning letters from four to six in the years 2008- 2013, to 10 in the year 2014, followed by a prominent rise in the number in the years 2015-2018. The number of countries has also increased. Table 2 and Figure 3 represents the percentage of warning letters related to data integrity in the past 10 years.
Table 3 represents the number of violations regarding the regulations cited in the warning letters in the years 2017 and 2018.

Laboratory Control Observations: The laboratory control associated observations are listed in Table 4 and Figure 4.

Manufacturing Control and Quality System Observations: The manufacturing control and quality system control associated observations are listed in Table 5 and Figure 5.

Analysis of 2008-18 FDA Warning Letters on Data Integrity

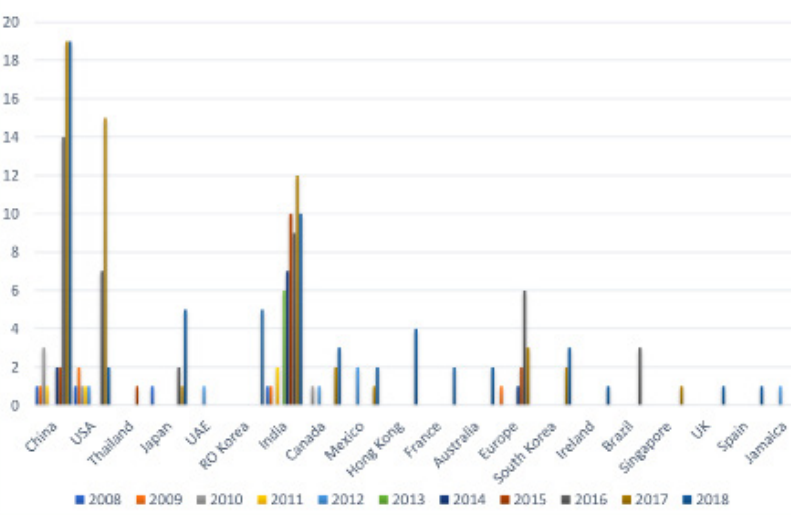

Figure 2: Number of Data Integrity Associated Warning Letters in the Years 2008-2018.

\begin{tabular}{|c|c|c|c|c|c|c|c|c|c|c|c|c|}
\hline Country & 2008 & 2009 & 2010 & 2011 & 2012 & 2013 & 2014 & 2015 & 2016 & 2017 & 2018 & TOTAL \\
\hline China & 1 & 1 & 3 & 1 & & & 2 & 2 & 14 & 19 & 19 & 62 \\
\hline USA & 1 & 2 & 1 & 1 & 1 & & & 0 & 7 & 15 & 2 & 30 \\
\hline Thailand & & & & & & & & 1 & & & & 1 \\
\hline Japan & 1 & & & & & & & 0 & 2 & 1 & 5 & 9 \\
\hline UAE & & & & & 1 & & & & & & & 1 \\
\hline RO Korea & & & & & & & & & & & 5 & 5 \\
\hline India & 1 & 1 & & 2 & & 6 & 7 & 10 & 9 & 12 & 10 & 58 \\
\hline Canada & & & 1 & & 1 & & & & & 2 & 3 & 7 \\
\hline Mexico & & & & & 2 & & & & & 1 & 2 & 5 \\
\hline Hong Kong & & & & & & & & & & & 4 & 4 \\
\hline France & & & & & & & & & & & 2 & 2 \\
\hline Australia & & & & & & & & & & & 2 & 2 \\
\hline Europe & & 1 & & & & & 1 & 2 & 6 & 3 & & 13 \\
\hline Ireland & & & & & & & & & & & 1 & 1 \\
\hline Brazil & & & & & & & & 0 & 3 & & & 3 \\
\hline Singapore & & & & & & & & & & 1 & & 1 \\
\hline UK & & & & & & & & & & & 1 & 1 \\
\hline Spain & & & & & & & & & & & 1 & 1 \\
\hline Jamaica & & & & & 1 & & & & & & & 1 \\
\hline South Korea & & & & & & & & & & 2 & 3 & 5 \\
\hline Total & 4 & 5 & 5 & 4 & 6 & 6 & 10 & 15 & 41 & 56 & 60 & 212 \\
\hline
\end{tabular}




\begin{tabular}{|c|c|c|}
\hline \multicolumn{3}{|c|}{$\begin{array}{c}\text { Table 2: Geographical Figures and Percentage in the } \\
\text { Years 2008-2018. }\end{array}$} \\
\hline Country & $\begin{array}{c}\text { total number } \\
\mathbf{2 0 0 8 - 2 0 1 8}\end{array}$ & $\begin{array}{c}\text { \% of total } \\
\mathbf{2 0 0 8 - 2 0 1 8}\end{array}$ \\
\hline China & 62 & $28.80 \%$ \\
\hline India & 58 & $26.90 \%$ \\
\hline United States & 30 & $13.95 \%$ \\
\hline Europe & 13 & $6.04 \%$ \\
\hline Japan & 9 & $4.18 \%$ \\
\hline Canada & 7 & $3.25 \%$ \\
\hline Mexico & 5 & $2.32 \%$ \\
\hline Rest of the world & 31 & $14.41 \%$ \\
\hline
\end{tabular}

\begin{tabular}{|c|c|}
\hline \multicolumn{2}{|c|}{ Table 4: Laboratory Control Observations- FDA } \\
Warning letters. & 1 \\
\hline Labelling & 2 \\
\hline False data recording & 2 \\
\hline Training & 3 \\
\hline Unknown peaks & 3 \\
\hline Data falsification & 3 \\
\hline Vendor management/materials & 4 \\
\hline Inadequate investigation & 4 \\
\hline Drug product closures and containers & 5 \\
\hline Unauthorised changes in e-data & 7 \\
\hline Delayed, denied or refused to FDA inspection & 7 \\
\hline Dissolution calibration/ De-aeration & 7 \\
\hline Laboratory tests & 10 \\
\hline Non-validated method & 11 \\
\hline Unofficial testing/ Trial injection & 12 \\
\hline Validation/ Quantification/ Calibration & 12 \\
\hline Laboratory data missing & 16 \\
\hline Computer system control & 16 \\
\hline Microbiological practices & 20 \\
\hline Incoming material testing & 32 \\
\hline Stability testing & 50 \\
\hline Documentation deficiencies/ SOPs not followed & \\
\hline
\end{tabular}

Figure 3: Geographical Figures and Percentage in the Years 2008-2018.

\begin{tabular}{|c|c|c|c|}
\hline \multicolumn{3}{|c|}{ Table 3: Regulations Cited in 2017 and 2018 Data } \\
Integrity Related Warning Letters. \\
\hline $\begin{array}{c}\text { 21 CFR } \\
\text { reference }\end{array}$ & Title of CFR section & $\begin{array}{c}\text { Number } \\
\text { of times } \\
\text { cited } \\
\mathbf{( 2 0 1 7 )}\end{array}$ & $\begin{array}{c}\text { Number } \\
\text { of times } \\
\text { cited } \\
\mathbf{( 2 0 1 8 )}\end{array}$ \\
\hline 211.22 & $\begin{array}{c}\text { Responsibilities of the } \\
\text { quality control unit }\end{array}$ & 3 & 11 \\
\hline 211.68 & $\begin{array}{c}\text { Automatic, mechanical } \\
\text { and electronic } \\
\text { equipment }\end{array}$ & 8 & 1 \\
\hline 211.165 & $\begin{array}{c}\text { Testing and release for } \\
\text { distribution }\end{array}$ & - & 12 \\
\hline 211.188 & $\begin{array}{c}\text { Batch production and } \\
\text { control records }\end{array}$ & 9 & 3 \\
\hline 211.192 & $\begin{array}{c}\text { Production record } \\
\text { review, deviations and } \\
\text { investigations }\end{array}$ & 5 & 6 \\
\hline 211.194 & $\begin{array}{c}\text { Laboratory records and } \\
\text { review of all data }\end{array}$ & 9 & 3 \\
\hline
\end{tabular}

\section{RESULTS AND DISCUSSION}

The number of warning letters received by different countries regarding data integrity has been represented in Figure 1 and Table 1.

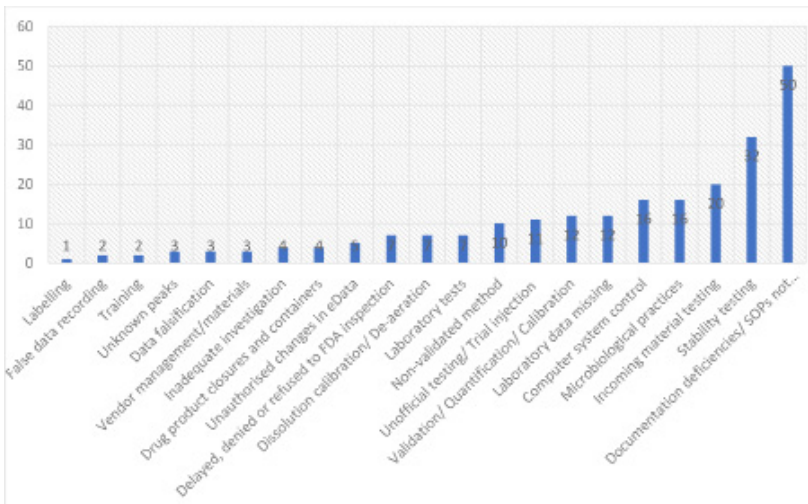

Figure 4: Laboratory Control Observations FDA Warning Letters.

There has been a marked increase in the number of warning letters from four to six in the years 2008-2013, to 10 in the year 2014, followed by a prominent rise in the number in the years 2015-2018. The number of countries has also increased.

According to Table 2 and Figure 3, sites in India and China have been subjected to the most warning letters of this type, whereas China leads the list.

During the inspection, regulators continue to find the same set of problems like sharing of passwords, no 


\section{Table 5: Manufacturing Control and Quality System} Observations - FDA Warning Letters.

\begin{tabular}{|c|c|}
\hline Penicillin contamination & 1 \\
\hline Contract employees training & 1 \\
\hline Labelling & 1 \\
\hline
\end{tabular}

\begin{tabular}{|c|c|}
\hline Labelling & 1 \\
\hline Torn GMP records in wastebin & 2 \\
\hline Failure of batch production & 2 \\
\hline
\end{tabular}

\begin{tabular}{|c|l|}
\hline Infrastructure (Wastearea) & 2 \\
\hline Batch release prior to review & 3 \\
\hline Unofficial BMR & 4 \\
\hline
\end{tabular}

\begin{tabular}{|c|c|}
\hline Unofficial BMR & 4 \\
\hline API of not standard quality & 4 \\
\hline Training & 6 \\
\hline
\end{tabular}

\begin{tabular}{|c|c|}
\hline Quality control & 6 \\
\hline Delayed, denied or refused to FDA & 6 \\
\hline FAR ratio & 7 \\
\hline
\end{tabular}

\begin{tabular}{|c|c|}
\hline FAR ratio & 7 \\
\hline Computer system control & 8 \\
\hline Inadequate investigation (media fill) & 8 \\
\hline Laboratory test & 8 \\
\hline
\end{tabular}

\begin{tabular}{|c|c|}
\hline Failure of quality & 8 \\
\hline Vendor management or materials & 9 \\
\hline Microbial contamination & 11 \\
\hline Maintenance & 12 \\
\hline BMR deficiencies & 14 \\
\hline Contamination control & 14 \\
\hline Inadequate investigation & 36 \\
\hline Validation/Qualification/Calibration & 42 \\
\hline Documentation deficiencies/ SOPs not followed & 51 \\
\hline
\end{tabular}

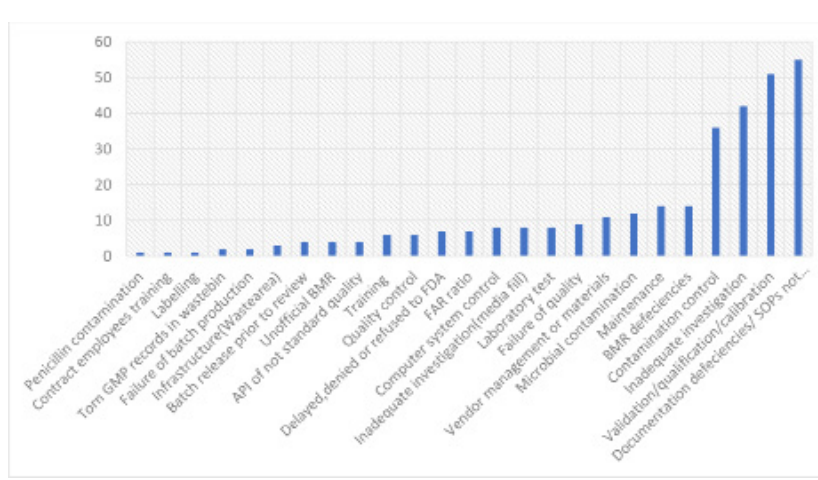

Figure 5: Manufacturing Control and Quality System Observations - FDA Warning Letters.

proper audit trails and lack of training. This raises the question of effective implementation of GMP regulations. Companies should give proper training to the employees, should increase the focus on data integrity during audits and periodic monitoring by the quality unit.

\section{CONCLUSION}

The industry must strongly consider any preventive or corrective action to improve the quality of product through enhanced data integrity and ethical behaviour. It is always better to be proactive rather than waiting for the regulators to identify breaches will never seem to be a sound strategy. Building a quality culture with proper planning and strategy will minimize problems related to data integrity. This will help in ensuring confidence and trust in regulators in the industry.

\section{ACKNOWLEDGEMENT}

The author would like to thank Manipal College of Pharmaceutical Science, MAHE for providing the materials and instruments to conduct this work.

\section{CONFLICT OF INTEREST}

The authors declare that there is no conflict of interest.

\section{ABBREVIATIONS}

USFDA: United State Food and Drug Administration; MHRA: The Medicines and Healthcare products Regulatory Agency; EMA: The European Medicines Agency; PIC/S: The Pharmaceutical Inspection Co-operation Scheme; WHO: World Health Organisation; GXP: Concept of Good practices.

\section{REFERENCES}

1. MHRA. GXP' Data Integrity Guidance and Definitions. MHRA Guide. 2018;(3):1-21.

2. Identifying and Preventing Common Data Integrity Issues. Master Control. 2019. [cited 4 April 2019]. Available from: https://www.mastercontrol.com/ gxplifeline/identifying-and-preventing-common-data-integrity-issues/

3. Interphex.com. 2019. [cited 4 April 2019]. Available from: https://www. interphex.com/RNA/RNA_Interphex_V2/2018/_docs/presentations/ INTERPHEX-2018-Data-Integrity.pdf?v=636633682855758647

4. Unger B. An Analysis of FDA Warning Letters on Data Governance and Data Integrity. Pharm Online. 2017;1-8. Available from: https://www. pharmaceuticalonline.com/doc/an-analysis-of-fda-warning-letters-on-datagovernance-data-integrity-0001

5. Rattan A. Data Integrity: History, Issues and Remediation of Issues. PDA Journal of Pharmaceutical Science and Technology. 2017;72(2):105-16.

6. Shafiei N, Montardy DR, Rivera-Martinez E. Data Integrity: A Study of Current Regulatory Thinking and Action. PDA Journal of Pharmaceutical Science and Technology. 2015;69(6):762-70.

7. 2008 Warning Letters. Wayback.archive-it.org. 2019. [cited 4 April 2019]. Available from: http://wayback.archiveit.org/7993/20170110235830/http:// www.fda.gov/ICECI/EnforcementActions/WarningLetters/2008/default. htm

8. Warning Letters. 2009. Wayback.archive-it.org. 2019. [cited 4 April 2019]. Available from: http://wayback.archiveit.org/7993/20170110235822/http:// www.fda.gov/ICECI/EnforcementActions/WarningLetters/2009/default. htm 
9. Warning Letters. 2010. Wayback.archive-it.org. 2019. [cited 4 April 2019]. Available from: http://wayback.archiveit.org/7993/20170110235812/http:// www.fda.gov/ICECI/EnforcementActions/WarningLetters/2010/default. $\mathrm{htm}$

10. Warning Letters. 2011. Wayback.archive-it.org. 2019 [cited 4 April 2019]. Available from: http://wayback.archiveit.org/7993/20170110235759/http:// www.fda.gov/ICECI/EnforcementActions/WarningLetters/2011/default.htm

11. Warning Letters. 2012. Wayback.archive-it.org. 2019. [cited 4 April 2019]. Available from: http://wayback.archiveit.org/7993/20170110235744/http:// www.fda.gov/ICECI/EnforcementActions/WarningLetters/2012/default.htm

12. Warning Letters. 2013. Fda.gov. 2019. [cited 4 April 2019]. Available from: https://www.fda.gov/ICECl/EnforcementActions/WarningLetters/2013/ default.htm

13. Warning Letters. 2014. Fda.gov. 2019. [cited 4 April 2019]. Available from: https://www.fda.gov/ICECl/EnforcementActions/WarningLetters/2014/ default.htm
14. Warning Letters. 2015. Fda.gov. 2019. [cited 4 April 2019]. Available from: https://www.fda.gov/ICECI/EnforcementActions/WarningLetters/2015/ default.htm

15. Warning Letters. 2016. Fda.gov. 2019. [cited 4 April 2019]. Available from: https://www.fda.gov/ICECI/EnforcementActions/WarningLetters/2016/ default.htm

16. Warning Letters. 2017. Fda.gov. 2019. [cited 4 April 2019]. Available from: https://www.fda.gov/ICECl/EnforcementActions/WarningLetters/2017/ default.htm

17. Warning Letters. 2018. Fda.gov. 2019 [cited 4 April 2019]. Available from: https://www.fda.gov/ICECI/EnforcementActions/WarningLetters/2018/ default.htm

18. Rachel P, Gupta N. Data Integrity - Regulations and Current Scenario. International Journal of Pharmaceutical Sciences Review and Research. 2017;16-22.

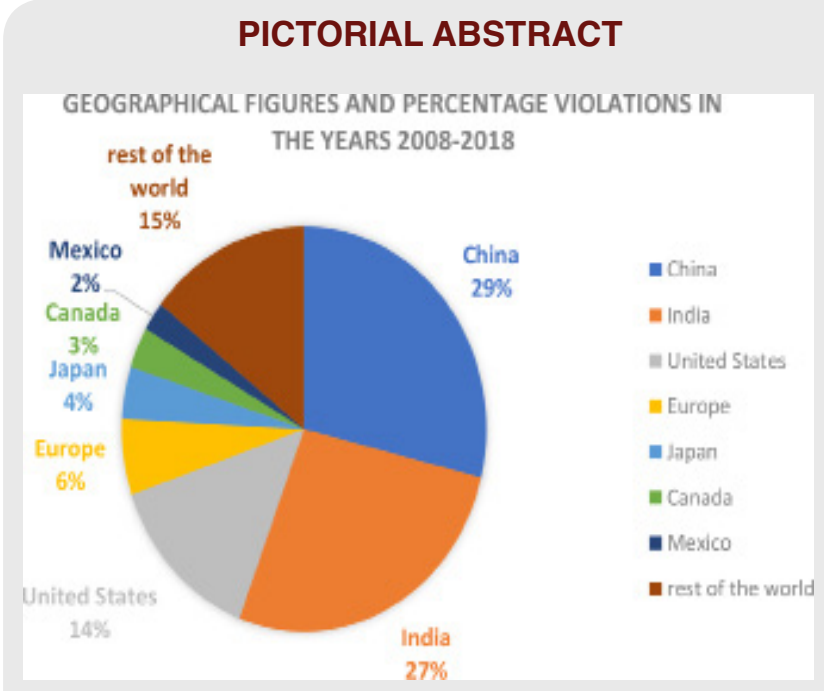 \\ SUMMARY \\ For the past 15 years, regulatory authorities have found many deficiencies in data integrity and data management. However, the number of warning letter issued and the number of countries has also increased over the years. The companies and industry have made little progress in recognizing and solving the issues. \\ About Authors

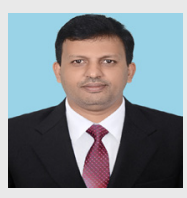 \\ Dr. Muddukrishna B.S: Is Associate Professor in Department of Pharmaceutical Quality Assurance, Manipal College of Pharmaceutical Sciences, Manipal Academy of Higher Education. He teaches pharmaceutical analysis to undergraduate students and pharmaceutical quality assurance and management to post graduate students of Pharmacy. He has $21+$ years of total experience in academics, Research \& Development, Laboratory Operations \& Quality Assurance in an organization of high repute. He has published several papers in journals of high repute and have presented papers in national and international conference.

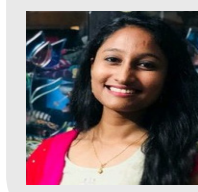 \\ Remya James: was a student of Manipal College of Pharmaceutical Sciences, Manipal Academy of Higher Education and completed her M. Pharmacy in Pharmaceutical Quality Assurance. She has presented papers in national conferences. She is presently working in one of the leading pharmaceutical company. \\ Cite this article: James R, Das S, Kumari A, Rekdal M, Kulyadi GP, Sathyanarayana MB. A Recent Regulatory Update on Consequences of Data Integrity Issues and its Management in Pharmaceutical Scenario. Indian $\mathrm{J}$ of Pharmaceutical Education and Research. 2021;55(2s):s616-s622.}

